\title{
The origin recognition complex has essential functions in transcriptional silencing and chromosomal replication
}

\author{
Catherine A. Fox, Stephen Loo, Andrew Dillin, and Jasper Rine \\ Department of Molecular and Cell Biology, Division of Genetics, University of California, Berkeley, California 94720 USA
}

\begin{abstract}
The role of the origin recognition complex (ORC) was investigated in replication initiation and in silencing. Temperature-sensitive mutations in ORC genes caused defects in replication initiation at chromosomal origins of replication, as measured by two-dimensional (2-D) origin-mapping gels, fork migration analysis, and plasmid replication studies. These data were consistent with ORC functioning as a eukaryotic replication initiator. Some origins displayed greater replication initiation deficiencies in orc mutants than did others, revealing functional differences between origins. Alleles of $O R C 5$ were isolated that were defective for silencing but not replication, indicating that ORC's role in silencing could be separated from its role in replication. In temperature-sensitive orc mutants arrested in mitosis, temperature-shift experiments caused a loss of silencing, indicating both that ORC had functions outside of the $\mathrm{S}$ phase of the cell cycle and that ORC was required for the maintenance of the silenced state.
\end{abstract}

[Key Words: ORC; silencing; cell cycle; replication; position effect; $S I R$; yeast; genetics]

Received September 22, 1994; revised version accepted March 9, 1995.

A central issue in eukaryotic DNA replication is the nature of events at replication origins, the positions on chromosomes at which DNA replication initiates. Replication initiation is a key control point in cell cycle progression, and identification of the proteins responsible for initiation at chromosomal origins is crucial to understanding the regulation of DNA replication in vivo. The yeast origin recognition complex (ORC) is a six-subunit protein complex that was purified based on its ability to bind specifically to yeast origins in vitro (Bell and Stillman 1992). Recent studies indicate that ORC is the best candidate for the yeast replication initiator (Bell and Stillman 1992; Diffley and Cocker 1992; Bell et al. 1993; Foss et al. 1993; Li and Herskowitz 1993; Micklem et al. 1993; Diffley et al. 1994).

In yeast there are at least two classes of replication origins. One class consists of those origins that seem devoted to replication initiation and have no obvious impact on the expression of nearby genes (Brewer and Fangman 1987). Most origins, including ARS1 and ARSH4, appear to be of this class. The other class consists of specialized origins that also have a role in controlling the expression of nearby genes. This specialized class has been defined by studies of the silent matingtype loci in yeast. In particular, the HMR-E silencer, a DNA sequence element required for repression at the HMR silent mating-type locus (Brand et al. 1985), is also a chromosomal origin (Rivier and Rine 1992a).

In yeast biology, silencers act to repress transcription of copies of the mating-type genes that reside at $H M L$ and $H M R$. Unlike at the expressed locus, $M A T$, matingtype genes at $H M L$ and $H M R$ are maintained in a repressed state by a process known as silencing. Silencing requires the actions of sequence elements that flank both $H M L$ and $H M R$, known as the $\mathrm{E}$ and I silencers (Abraham et al. 1982; Feldman et al. 1984), as well as a combination of proteins including Sirlp, Sir2p, Sir3p, Sir4p, and histone H4 (Rine and Herskowitz 1987; Kayne et al. 1988; for review, see Laurenson and Rine 1992).

The $H M R$-E silencer is both necessary and sufficient to repress transcription of the a mating-type genes present at $H M R$ (Abraham et al. 1984). HMR-E consists of binding sites for the RAPl and ABFl proteins and two ARS elements (Brand et al. 1987; Kimmerly 1988). ARS (auutonomously replicating sequence) elements are defined by their ability to confer autonomous replication to plasmids, and some ARS elements are chromosomal origins of replication. Mutations in the $H M R$-E silencer cause silencing-defective phenotypes only in double mutant combinations because of functional redundancy among the elements of the silencer (Brand et al. 1987; Kimmerly 1988). To enhance the genetic dissection of silencer function, a synthetic silencer was created by joining oligonucleotides containing only one ARS consensus sequence (ACS), a RAPl site, and an ABFl site (McNally and Rine 1991). The synthetic silencer is as effective at silencing HMRa yet lacks much of the redundancy that complicates studies of natural $H M R$-E. Unlike mutations in the natural $H M R$-E silencer, mutations of either the ACS or the RAP1 site of the synthetic si- 
lencer result in loss of silencer function (McNally and Rine 1991).

Several independent lines of evidence have indicated a connection between DNA replication and silencing (for review, see Rivier and Rine 1992b). For example, both the natural $H M R-E$ silencer and the synthetic silencer function as chromosomal origins of DNA replication (Rivier and Rine 1992a). Second, mutation of the ACS in the synthetic silencer abolishes both silencing and origin function of the synthetic silencer (McNally and Rine 1991; Rivier and Rine 1992a). Third, temperature-sensitive mutations in ORC2 and ORC5 cause derepression of $H M R$ (Foss et al. 1993; Micklem et al. 1993; S. Loo, C. Fox, J. Rine, R. Kobayashi, B. Stillman, and S. Bell, in prep.).

Silencing consists of two distinguishable steps: the establishment and the maintenance of the silent state. Establishment requires passage through $\mathrm{S}$ phase (Miller and Nasmyth 1984), further suggesting a relationship between DNA replication and silencing. After the initial establishment event, the silenced state is maintained and inherited for multiple mitotic generations independent of at least one protein required for establishment (Pillus and Rine 1989). Because silencers participate in the establishment of the silenced state and ORC binds to silencers, ORC could have a role in establishing the silenced state (Mahoney et al. 1991; Sussel et al. 1993). If ORC is the replication initiator, then replication initiation itself could have a role in silencing.

In this paper we examined three issues concerning the role of ORC in chromosomal initiation and silencing. First, we determined whether ORC functions in chromosomal initiation at specific origins. Second, we examined the connection between ORC's roles in DNA replication and silencing and determined whether the two roles were separable. Third, we determined whether ORC had a role in the maintenance of the silent state independent of its role in replication.

\section{Results}

The identification of mutations in two subunits of the ORC by their silencing defect deepens the connection between DNA replication and silencing but does not re- veal the mechanism of that connection. Therefore, the effect of mutations in $O R C 2$ and $O R C 5$ on replication initiation and silencing was evaluated.

\section{ORC was required for efficient replication initiation from ARS1}

If ORC is the replication initiator, then defective ORC subunits should cause a detectable decrease in chromosomal initiation in vivo. ARS1 is the most thoroughly characterized origin in the yeast genome, and information obtained from studies of $A R S 1$ has been applicable to other yeast origins (Marahrens and Stillman 1992). Therefore, we tested whether mutations in ORC genes affected replication initiation at chromosomal ARS1. $O R C$ genes are essential for viability, precluding testing the effect of null alleles in these experiments (Foss et al. 1993; Micklem et al. 1993; S. Loo et al., in prep.). Therefore, conditionally lethal alleles of $O R C$ genes were used to evaluate origin function in cells grown at the permissive temperature. Despite the residual ORC function in cells grown in this manner, orc2-1 and orc5-1 decreased replication initiation at $A R S 1$, as judged by the decreased ratio of bubble forms to small fork forms on two-dimensional origin-mapping gels (Fig. 1).

\section{$O R C$ was required for replication initiation from the synthetic silencer}

The synthetic silencer is a chromosomal origin that requires an ACS for both silencing and replication initiation (McNally and Rine 1991; Rivier and Rine 1992a). If there is a simple relationship between ORC's role in replication and its role in silencing, defects in ORC that decrease silencing should decrease the efficiency of replication initiation from the synthetic silencer. The effect of orc2-1 and orc5-1 on replication initiation at the synthetic silencer was compared with the effect of a mutation in the ACS. As demonstrated previously (Rivier and Rine 1992a), mutation of the ACS in the synthetic silencer completely abolished origin function (Fig. 2B, 1 and 2). Similarly, orc2-1 severely diminished initiation of replication (Fig. 2B, 3) but not as drastically as did removal of the ACS. Thus, the defect in orc2-1, identi-

Figure 1. ORC was required for efficient replication initiation from $A R S 1$. Replication initiation was monitored at $A R S 1$ in isogenic $O R C$, orc2-1, and orc5-1 strains (JRY4473，JRY4475，JRY4476). (1) How two-dimensional origin-mapping gels distinguish replication initiation at origins from replication forks. Origin activity is reflected by the ratio of replication bubbles to small forks (Brewer and Fangman 1987). The DNA in 2-4 was digested with Ncol, and the ARS1-containing fragment was detected with probes made to the EcoRI TRP1-ARS1 fragment.

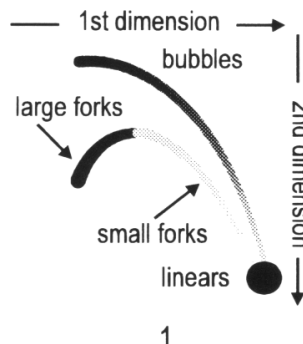

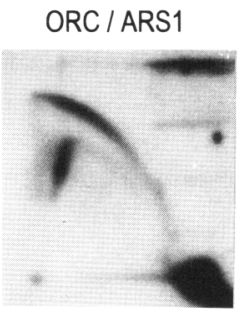

2

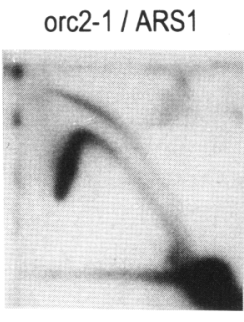

3 orc5-1 / ARS1

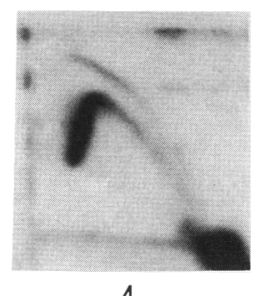

4 


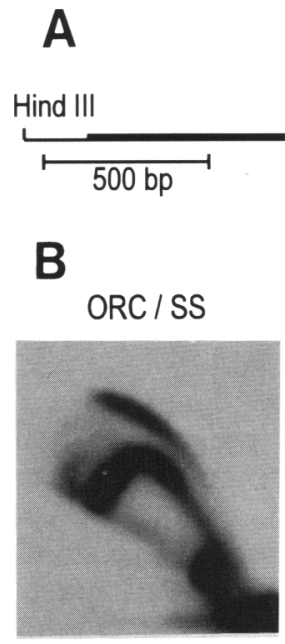

1

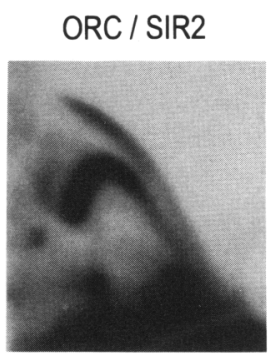

5
ORC / SSars

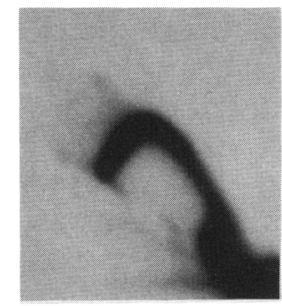

2

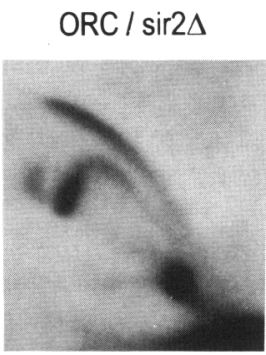

6 synthetic silencer: ARS RAP1 ABF1

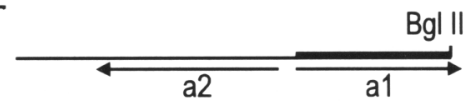

orc2-1 / SS

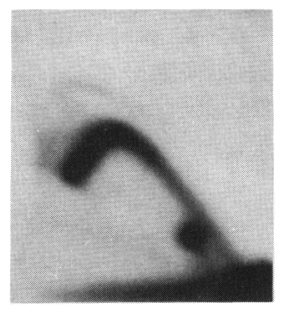

3

orc2-1 / sir2 $\triangle$

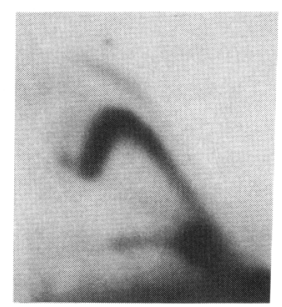

7 $\operatorname{orc5-1}$ / SS

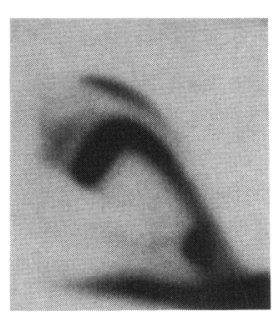

4

orc5-1 / sir2 $\Delta$

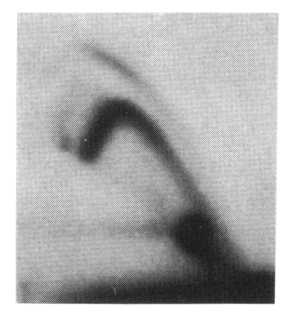

8
Figure 2. ORC was required for replication initiation from the synthetic silencer. (A) Diagram of the HindIII-BglII $H M R$ fragment examined in these experiments. The probes used to detect this fragment are indicated by bold lines. $(B)$ Results of a two-dimensional origin experiment. A HindIII-Bglll fragment spanning HMR-E was analyzed for the presence of replication intermediates. $(1-4)$ The results from a set of isogenic $M A T \alpha$ strains containing HMR-SS $\triangle \mathrm{I}$ at $H M R$ and either wild-type $O R C$ or orc mutations. The ars ${ }^{-}$in 2 refers to the ACS mutation described previously (McNally and Rine 1991). The strains used to generate 1-4 were JRY4473， JRY4474, JRY4475, and JRY4476, respectively. (5-8) The results from a set of isogenic MAT $\alpha$ strains containing $H M R$-SS $\triangle \mathrm{I}$ at $H M R$ and either wild-type $O R C$ or orc mutations. The strains used to generate $6-8$ also contain a null mutation in the chromosomal copy of SIR2. The strains used to generate 5-8 were JRY4473, JRY4477, JRY4478, and JRY4479, respectively. fied by its effect on silencing, was paralleled by a defect in replication initiation. The residual replication initiation observed at the synthetic silencer in orc2-1 mutants was less than at ARS1 and provided additional evidence that ORC was a yeast initiator complex.

The decrease in replication initiation at the synthetic silencer caused by orc5-1 was qualitatively similar to the effect of orc2-1 (Fig. 2B, panels 1 and 4). However, the reduction in replication initiation caused by orc5-1 at this origin was consistently smaller than that caused by orc2-1 (Fig. 2B, panels 3 and 4; Table 1). This result was the opposite of that observed for ARS1, where orc5-1

Table 1. Plasmid loss rates

\begin{tabular}{lccc}
\hline & ORC \pm S.D. & orc2-1 \pm S.D. & orc5-1 \pm S.D. \\
\hline SS & $0.037 \pm 0.01$ & no transformants & $0.216 \pm 0.015$ \\
ARS1 & $0.004 \pm 0.008$ & $0.037 \pm 0.014$ & $0.101 \pm 0.028$ \\
ARSH4 & $<0.001$ & $0.011 \pm 0.009$ & $0.044 \pm 0.012$
\end{tabular}

Loss rates of plasmids replicated by different origins in isogenic ORC (JRY3009), orc2-1 (JRY4125), and orc5-1 (JRY4249) strains are shown. DNA fragments containing the synthetic silencer, $A R S 1$, or ARSH4 served as the sole origins of replication on these plasmids. In the case of the synthetic silencer containing plasmid in the orc2-1 strain, prototrophs arising on the transformation plate did not form colonies upon restreaking. caused a slightly more severe defect in initiation than did orc2-1 (Fig. 1; Table 1).

One major difference between $A R S 1$ and $H M R$-E is that the HMR locus is silenced and ARS1 is not. To determine whether the transcriptional state of the locus affected replication initiation in orc mutants, replication initiation was evaluated in an isogenic set of strains containing the synthetic silencer and a deletion of the SIR2 gene. The effect of orc2-1 and orc5-1 on replication initiation from the synthetic silencer was similar in SIR2 and sir $2 \Delta$ cells (Fig. 2B, 5-8). Thus, the reduced initiation at the synthetic silencer caused by the orc2-1 and orc5-1 mutations was not attributable to a reduction in silencing.

\section{$O R C$ was required for the replication of plasmids}

DNA fragments that contain a chromosomal origin of replication allow plasmids to replicate. With plasmids that contain a centromere and hence segregate efficiently, the rate of plasmid loss is a measure of origin function. Moreover, origin function as determined by the rate of plasmid loss can be quantified more accurately than can two-dimensional origin-mapping gels. For plasmid loss-rate experiments, three centromere-containing plasmids were used that each contained a different origin of replication: ARS1, ARSH4, or the synthetic silencer. 
Fox et al.

The rate of plasmid loss was determined for each plasmid in wild-type cells and in orc mutants grown at the permissive temperature (Table 1).

Plasmids replicated by $A R S 1$ or by $A R S H 4$ were lost in wild-type cells at a low rate, as expected (Campbell and Newlon 1991). The loss rate for these plasmids increased 10- to 25-fold in orc2-1 and orc5-1 mutants, respectively. The loss rate of plasmids replicated by the synthetic silencer was higher than the loss rate of plasmids replicated by ARS1 or ARSH4, even in wild-type cells. Nevertheless, in orc5-1 cells, the loss rate of the plasmid replicated by the synthetic silencer was fivefold higher than in wild-type cells, and in orc2-1 cells, the loss rate was too high to allow for the restreaking of primary transformants. In summary, the results from plasmid loss rate measurements paralleled the results from twodimensional origin-mapping gels and indicated strongly that origin function was severely compromised in orc mutants.

\section{Fork migration analysis revealed defects in chromosomal initiation at the synthetic silencer and at ARSl origins in orc mutants}

The preceding data consistently showed that orc mutations caused defects in chromosomal initiation at both the synthetic silencer and ARS1 origins. To provide a third independent measure of origin function in orc mutants, we performed fork migration analysis on sequences immediately flanking the origins of interest.

The fraction of cell cycles in which an origin initiates replication determines the direction of the replication fork that replicates flanking sequences. Consider the direction of fork migration between two origins on the same chromosome (Fig. 3A). If the origin on the right fires in every cell division, the sequences immediately to its left will be replicated by a fork moving from the right to the left. If for some reason the right origin fails to fire and those same sequences are replicated by a fork starting at the left origin, then the fork will move from the left to the right. An adaptation of two-dimensional origin-mapping gels can be used to measure the direction of fork migration through the sequences of interest (Brewer and Fangman 1991). After separation by size in the first dimension, the replication intermediates are digested in the gel with a second enzyme that cuts within the fragment of interest. The DNA is then separated on the basis of shape (second dimension), and the fragment is detected with a specific probe. If the right origin fires every cell cycle, then a fragment immediately adjacent to this origin will produce a fork, after in-gel digestion, that is smaller and that is displaced vertically downward (reflecting decreased size/ from the original undigested fork (Fig. 3A, first and second panels). In contrast, if the right origin never fires and the fragment is instead replicated by a fork coming from the left origin, the fork produced by digestion in the gel will be displaced both vertically (reflecting decreased size) and horizontally (reflecting trimming off of small forks) from the original undigested fork (Fig. 3A, third panel). The orc mutants retain some origin function at both the synthetic silencer and ARS1 origins (Figs. 1 and 2). However, if the decrease in the amount of bubble intermediates in orc mutants is the result of decreased initiation, then fork migration analysis should reveal the appearance of two new forks, one displaced vertically (a result of residual initiation from the origin of interest) and one displaced both horizontally and vertically from the original fork la result of the fragment being replicated from a fork coming from another origin) (Fig. 3A, fourth panel).

Fork migration analyses were performed on sequences immediately flanking the left side of the synthetic silencer in both wild-type $O R C$ and orc mutant strains to determine whether these analyses of origin function agreed with the other two analyses (Fig. 3B). In most wild-type cells, the sequences flanking the left side of the synthetic silencer were replicated by a fork coming from the direction of the synthetic silencer (Fig. 3B, 1 and 2). A small amount of horizontally displaced forks could also be detected $(\sim 10 \%$ of total) that were slightly more visible on the original image, indicating a few forks moving from left to right. Similar analysis of the sequences to the right of the synthetic silencer (not shown) indicated that the synthetic silencer initiated replication in $\sim 80-90 \%$ of cell cycles.

The analysis of fork migration in cells harboring an ARS consensus mutation of the synthetic silencer, which abolishes the function of this origin $(\mathrm{McNally}$ and Rine 1991; Rivier and Rine 1992a; this paper; Fig. 2) led to a different picture. In this mutant, analysis of sequences to the left of the synthetic silencer revealed a dramatic increase in the amount of horizontally displaced forks (Fig. 3B, 3 and 4). In $\sim 50 \%$ of cell cycles, the sequences immediately to the left of the synthetic silencer were replicated by a fork moving from the left to the right from an origin farther to the left. In the remainder of cell cycles, these sequences were replicated from right to left. This interpretation was confirmed by analysis of sequences to the right of the mutant synthetic silencer (not shown). These data confirmed that the ARS consensus mutation completely abolished origin function of the synthetic silencer and indicated the existence of an uncharacterized origin that was to the right of the synthetic silencer.

The effects of orc2-1 and orc5-1 on initiation from the synthetic silencer paralleled the effects of the ACS mutation. In both orc2-1 and orc5-1 mutants, analysis of fork migration left of the synthetic silencer revealed an increase in the amount of horizontally displaced forks (Fig. 3B, 5-8). orc5-1 produced a pattern very similar to that caused by the ACS mutation, and orc2-1 caused a less dramatic effect. Interestingly, quantitation of fork migration analysis of sequences flanking the right side of the synthetic silencer indicated that in orc5-1 mutants these sequences were replicated in $\sim 70 \%$ of cell cycles by forks coming from the direction of the synthetic silencer, whereas in orc2-1 mutants these same sequences were replicated in only $\sim 20 \%$ of cell cycles by forks coming from the direction of the synthetic silencer (not shown). Together with the data presented in Figure 3B, 


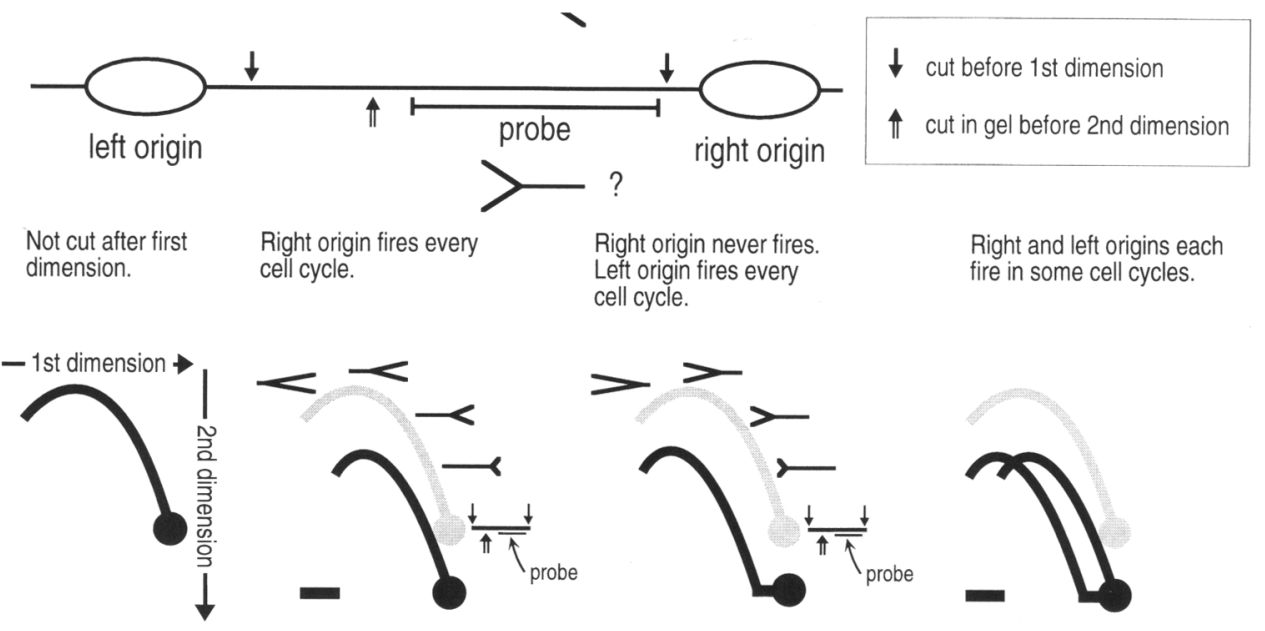

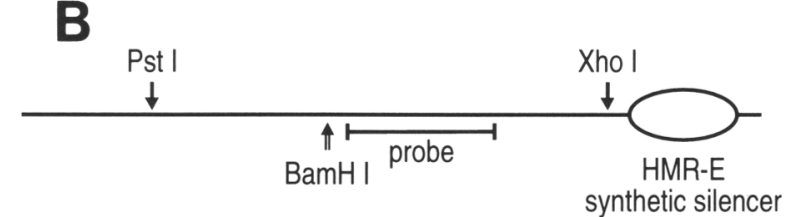

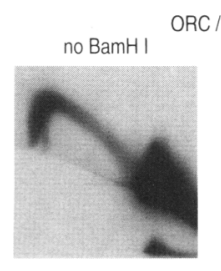

1

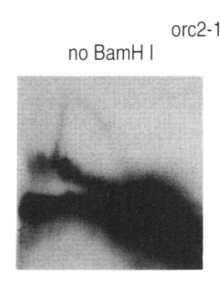

5

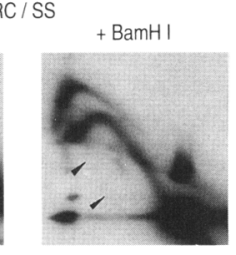

2

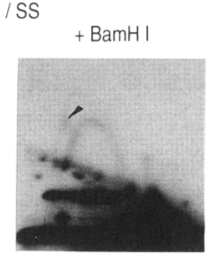

6
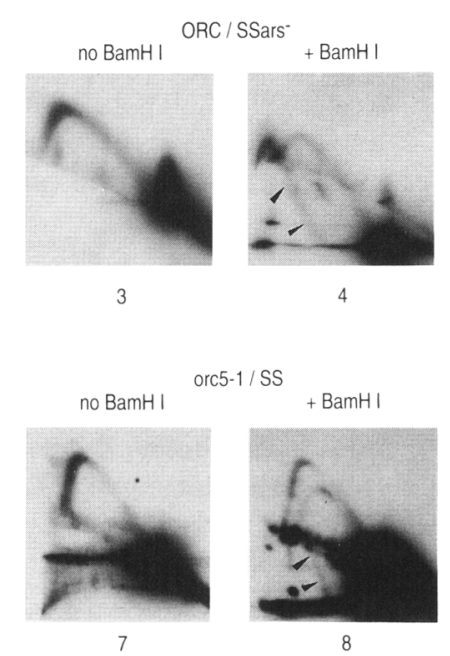

orc5-1/ SS

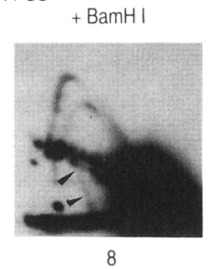

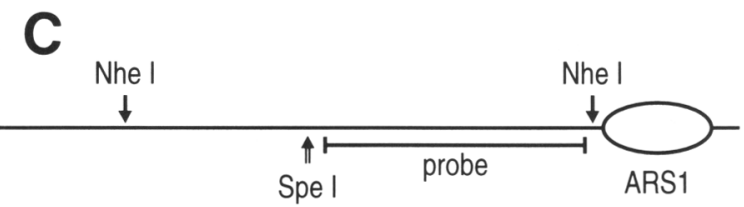

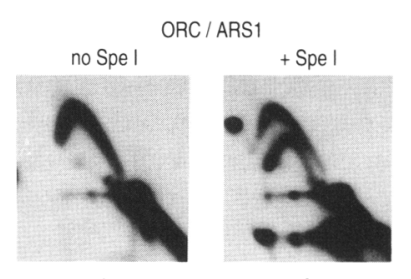

2

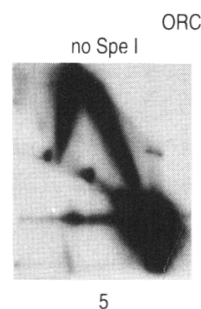

RC / ARS 1

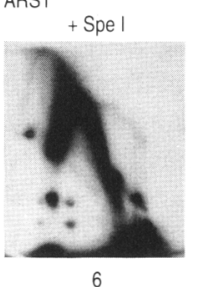

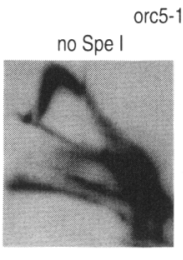

3

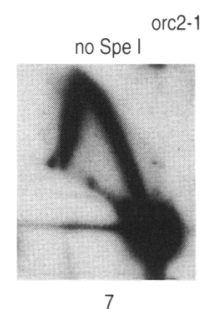

orc2-1/ ARS1

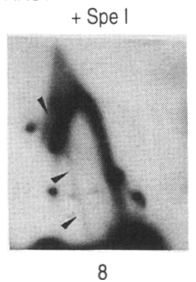

Figure 3. Fork migration analyses in orc mutants. $\langle A$, top $|$ Two origins of replication on the same chromosome. The sequences immediately to the left of the right-hand origin are replicated by a replication fork moving from right to left (upper fork) in cell cycles in which that origin initiates replication. In cell cycles in which that origin fails to initiate replication, those sequences are replicated

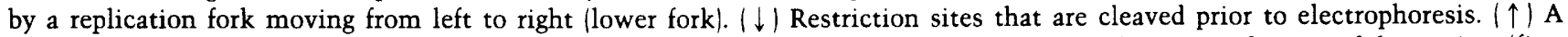
restriction site cleaved in the gel after electrophoresis in the first dimension and before electrophoresis in the second dimension. (first panel) A schematic representing the mobility of the restriction fragment immediately to the left of the origin on the right, as revealed by hybridization to the indicated probe. (second panel) The altered mobility as a result of restriction digest in the gel at the indicated site prior to electrophoresis in the second dimension if the right origin fires in every cell cycle. (Third panel) The right origin does not fire and the same sequences are replicated from a fork moving from the direction of the left origin. Upon cleavage in the gel and two-dimensional electrophoresis, the forks are smaller and displaced to the left. (Fourth panel) A situation in which the sequences of interest are replicated from left to right in some cells and from right to left in other cells. Note that incomplete digests will still contain some undigested fork, which can serve as an internal marker of the original fork. This does not affect interpretation because sequences containing forks moving from either direction are cleaved equally well (Brewer and Fangman 1991) This schematic is adapted from Brewer and Fangman (1991). (B, top) These experiments evaluate the migration of replication forks through the PstI-XhoI fragment immediately to the left of the synthetic silencer at HMR. The 1.4-kb EcoRI fragment from HMR was used as probe. (Bottom) (1 and 2) The fork migration through this region in ORC cells with an intact synthetic silencer (JRY4473). Most forks move from right to left, but note the faint fork representing molecules replicated from left to right. Note incomplete digest. ( 3 and 4$)$ In cells with a defective ACS at the synthetic silencer (JRY4474), the sequences of interest are replicated from left to right ( $~ 50 \%)$ and from right to left $(\sim 50 \%)$. (5 and 6) The effect of orc2-1 (JRY4475); and (7 and 8) the effect of orc5-1 (JRY4476). (C, top) The experiments evaluate the migration of replication forks through the NheI fragment adjacent to ARS1. The 3-kb Ncol-Nhel fragment from TRP1-ARS1 was used as probe. (Bottom) This analysis is similar to that in $B$, except that 5 and 6 are long exposures of a similar experiment [genomic DNA from the same strain (JRY4473) run on a different gel] to that shown in 1 and 2. The DNA in these experiments was isolated from the same strains used in $B$, above. 
Fox et al.

these data suggested that orc5-1 mutants initiated replication at the synthetic silencer in $-20-30 \%$ of cell cycles and orc2-1 mutants initiated replication at this same origin in $<10-20 \%$ of cell cycles. These data provided further evidence that both orc2-1 and orc5-1 caused a decrease in chromosomal initiation from the synthetic silencer origin.

To extend the analysis of the effects of orc2-1 and orc5-1 on chromosomal initiation, we also performed fork migration analysis on fragments flanking ARS1. Both orc mutations retained the ability for a significant amount of initiation at ARS1. Nevertheless, for both mutations, a new horizontally displaced fork was observed (Fig. 3C, 3,4,7, and 8) that was not observed in wild-type cells (Fig. 3C, 1 and 2) even after very long exposures (Fig. 3C, 5 and 6). Analysis of both sides of ARS1 indicated that this origin initiated in $\sim 100 \%$ of cell cycles in wild-type cells (Fig. 3C; quantitation by PhosphorImager analysis), consistent with published reports (Brewer and Fangman 1991, 1993). The appearance of horizontally displaced forks in orc mutants indicated that sequences immediately adjacent to $A R S 1$, which were never replicated by an origin other than ARS1 in wild-type cells, were replicated in $\sim 30 \%$ of cell cycles by a replication fork coming from a centromere-proximal origin in orc mutants under permissive growth conditions. These data provided unequivocal evidence that orc2-1 and orc5-1 mutations decreased initiation from the $A R S 1$ origin of replication in vivo.

\section{ORC was required for silencing of HMRa}

If the role of ORC in silencing were a simple manifestation of its role in replication initiation, then the effect of orc mutations on silencing should parallel their effect on replication initiation. To measure the effect of orc mutations on silencing at $H M R$ a, we compared the mating properties of an isogenic set of MAT $\alpha$ strains containing the acs ${ }^{-}$synthetic silencer with strains containing the synthetic silencer combined with $O R C$, orc2-1, or orc 5-1 alleles. The $H M R$-I element was deleted from these strains. As shown previously, cells containing a muta- tion in the ACS of the synthetic silencer exhibited a severe silencing defect as judged by the low mating efficiency (McNally and Rine 1991). Similarly, the orc2-1 and orc5-1 mutations reduced mating efficiency, although not as severely as removal of the ACS from the synthetic silencer. As an independent and more direct measure of silencing, the level of mRNA from the a1 gene at $H M R$ was measured in these strains by RNA blot hybridization (Fig. 4B).

If the primary role of ORC in silencing were replication initiation, then the smaller effect of orc5-1 than orc2-1 on replication initiation would suggest that orc $5-1$ should cause a more modest silencing defect than orc2-1. However, the qualitative tests of mating efficiency revealed virtually identical effects of these two mutations, as did the RNA analysis (Fig. 4). Similarly, a quantitative efficiency of mating experiment also indicated that the effects of orc2-1 and orc5-1 on silencing were virtually identical (Table 2). Moreover, in strains that contained both the synthetic silencer and the $H M R$-I element, orc5-1 caused a more severe defect in silencing than did orc2-1 (Fig. 7, below; Table 2), which was contrary to the relative effect of these two orc mutations on replication initiation from the synthetic silencer (Fig. 2; Table 1), suggesting that the relationship between ORC and silencing was not simply a reflection of ORC in replication initiation.

\section{The natural HMR-E silencer was insensitive to orc mutations}

The natural $H M R$-E silencer has a degree of redundancy missing in the synthetic silencer because it contains at least two functional ARS elements and multiple near matches to the ACS. Furthermore, mutations in two of its sequence elements are required to cause a loss of silencing (Brand et al. 1987; Kimmerly 1988). In quantitative mating assays (Table 2) as well as RNA blot hybridization (Fig. 5A), neither orc2-1 nor orc5-1 caused derepression of $H M R \mathbf{a}$ in cells containing a wild-type $H M R$-E silencer. This result would break the connection be-
A

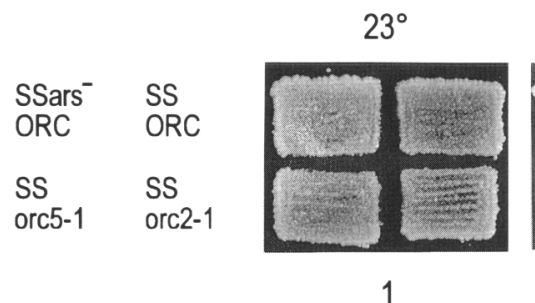

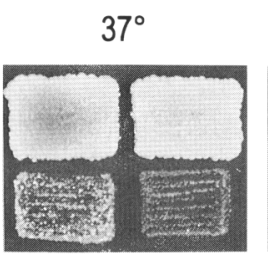

2

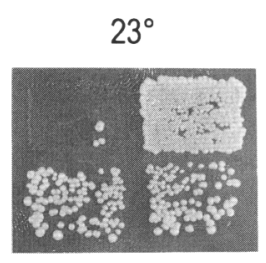

3
B

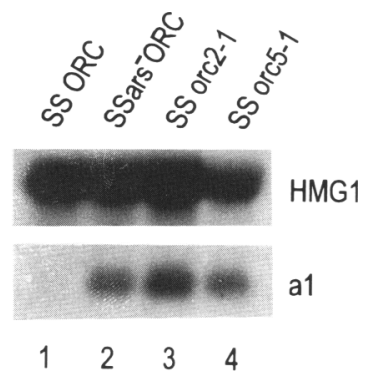

Figure 4. ORC was required for silencing of $H M R \mathbf{a}$. (A) Isogenic MAT $\alpha$ strains were grown on rich medium at $23^{\circ} \mathrm{C}$ for $12 \mathrm{hr}$ and were then replica-plated to rich medium at $23^{\circ} \mathrm{C}$ (panel 1$), 37^{\circ} \mathrm{C}$ (panel 2), and to minimal medium containing a lawn of a cells at $23^{\circ} \mathrm{C}$ (panel 3). Growth of cells in panel 3 reflected the extent of mating with cells in the a lawn. (B) An RNA-blotting experiment was used to monitor repression of $H M R$ by the amount of a 1 mRNA produced. Total RNA was isolated from log-phase yeast cells. The relevant genotype is indicated above each lane. $H M G 1$ served as a loading control. The strains used in the experiments in both $A$ and $B$, labeled above the RNA-blotting experiment, from left to right were JRY4473, JRY4474, JRY4475, and JRY4476. 
Table 2. Mating efficiencies

\begin{tabular}{|c|c|c|c|}
\hline Silencer (expt.) & $O R C \pm S . D$ & orc2-1 \pm S.D. & orc5-1 1 S.D. \\
\hline$H M R-S S \Delta I(1)$ & $0.14 \pm 0.02$ & $2.0 \times 10^{-3} \pm 1.5 \times 10^{-5}$ & $3.1 \times 10^{-3} \pm 1.2 \times 10^{-3}$ \\
\hline$H M R-\mathrm{SS} \Delta \mathrm{I}(2)$ & $0.22 \pm 0.02$ & $1.6 \times 10^{-3} \pm 5.6 \times 10^{-4}$ & $2.8 \times 10^{-3} \pm 0$ \\
\hline$H M R-\mathrm{SS} \Delta \mathrm{I}(3)$ & $0.057 \pm 0.006$ & $1.4 \times 10^{-3} \pm 5.6 \times 10^{-4}$ & $1.2 \times 10^{-3} \pm 3.5 \times 10^{-4}$ \\
\hline$H M R$-SSars $^{-} \Delta \mathrm{I}$ & $6.5 \times 10^{-6} \pm 4.6 \times 10^{-6}$ & N.D. & N.D. \\
\hline$H M R-S S+I(1)$ & 1.2 & $0.76 \pm 0.18$ & $0.061 \pm 0.022$ \\
\hline$H M S-S S+I(2)$ & 1.0 & $0.54 \pm 0.17$ & $0.32 \pm 0.027$ \\
\hline$H M R-\mathrm{E} \Delta \mathrm{I}$ & 0.95 & 1.1 & 0.98 \\
\hline$H M R$-ARS1 $\Delta \mathrm{I}$ & $1.8 \times 10^{-6} \pm 1.5 \times 10^{-6}$ & N.D. & N.D. \\
\hline$H M R-A R S H 4 \Delta I$ & $8.6 \times 10^{-6} \pm 1.6 \times 10^{-6}$ & N.D. & N.D. \\
\hline
\end{tabular}

Quantitative mating assays were performed with the strains used for this paper. Strains to be tested were mated with an excess of a mating-type cells (JRY2726), and diploids were selected on minimal medium at $23^{\circ} \mathrm{C}$. The strains labeled $H M R$-SS $\Delta \mathrm{I}$ contained the synthetic silencer at $H M R$-E and lacked $H M R$-I. Strains labeled $H M R-\mathrm{SS}$ ( + I), contained the synthetic silencer at $H M R$-E and contained $H M R$-I. In most experiments, values were obtained for multiple dilutions of the tester cells and different values arising from different dilutions or from duplicate platings of the same tester cells were averaged and the standard deviation reported. Although absolute values varied from one day to the next, the relative differences were constant. (N.D.) Not determined.

tween silencing and replication initiation at $H M R-E$ if the orc mutations blocked replication initiation at $H M R$ E. Alternatively, $H M R$-E may be a complex origin capable of functioning normally under reduced levels of ORC function. To distinguish between these possibilities, replication initiation at the $H M R-E$ silencer was evaluated directly in wild-type, orc2-1, and orc5-1 strains. By twodimensional origin-mapping gels, neither orc2-1 nor orc5-1 caused a decrease in replication initiation at $H M R$-E (Fig. 5B). Thus, $H M R$-E required less ORC function for efficient replication initiation than did either $A R S 1$ or the synthetic silencer. Furthermore, the transcriptional state at $H M R$ did not influence the effects of orc2-1 and orc5-1 on replication initiation /data not shown).

\section{Replication initiation at HMR was not sufficient to provide any silencing function}

To test directly whether origin function at $H M R$-E was sufficient for silencing of $H M R$, we replaced the chromosomal $H M R$-E silencer with two different, well-characterized origins of replication, ARS1 and ARSH4, and tested the ability of these origins to initiate replication and promote silencing at this new location. Based on two-dimensional origin-mapping gels, both ARS1 and ARSH4 were capable of initiating replication when used to replace HMR-E (Fig. 6; data not shown). Moreover, the efficiency of replication initiation by ARS1 was similar to initiation at its normal chromosomal location. However, based on quantitative efficiency of mating experiments, neither ARS1 nor ARSH4 provided any silencing function (Table 2). Thus, wild-type ORC function at the site of $H M R-\mathrm{E}$, as measured by replication initiation, was not sufficient to cause even a small amount of silencing.

\section{ORC5 had genetically separable silencing and initiation functions}

Two independent revertants of an orc5-1 strain were isolated that were able to grow at $37^{\circ} \mathrm{C}$. These revertants grew at the restrictive temperature at a rate that was indistinguishable from wild type (Table 3 ) but failed to rescue the silencing defect. The two revertants were crossed to a wild-type strain (JRY4012), and the meiotic products were evaluated to determine whether the reversion was the result of a change in ORC5 itself or in another gene. No temperature-sensitive recombinants were recovered among 18 complete tetrads from each of the two crosses. Therefore, the mutations responsible for growth at high temperature were very close to the orc5-1 lesion $(\leqslant 2.7 \mathrm{cM})$. DNA sequence revealed that the pseudorevertant phenotype was the result of mutations
A

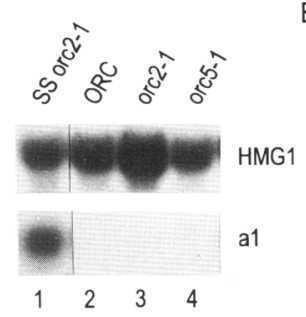

B

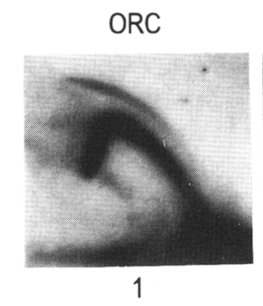

orc2-1

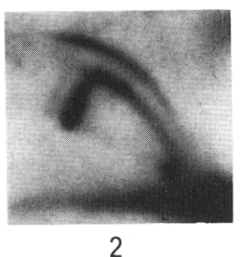

orc5-1

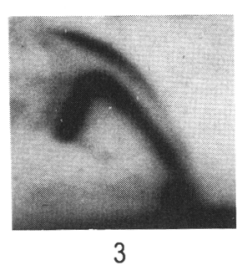

Figure 5. The natural HMR-E silencer was insensitive to orc mutations. (A) Total RNA was isolated from log-phase yeast cells containing either natural $H M R-\mathrm{E}$ (lanes $2-4)$ or the synthetic silencer $(\Delta \mathrm{I}$; lane 1) and the $O R C$ genotype indicated. The a1 mRNA served to measure the extent of repression at $H M R$, and the $H M G 1$ mRNA served as a loading control. $(B)$ Results of a two-dimensional origin-mapping experiment evaluating replication initiation in the HindIII-BglII fragment containing HMR-E. The ORC genotype is indicated at the top. The strains used in these experiments from left to right were JRY4480, JRY4481, and JRY4482. 

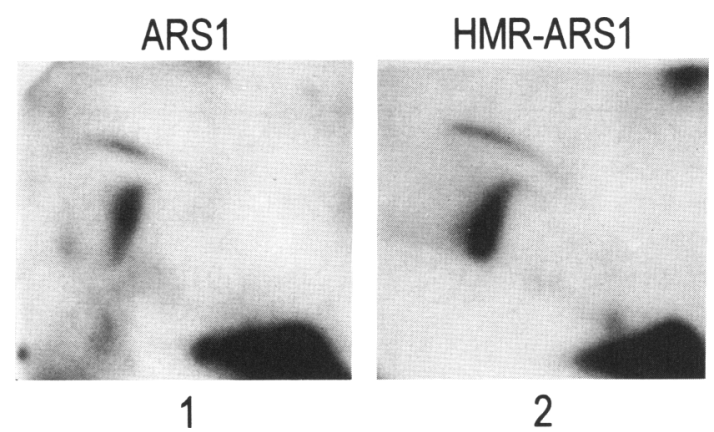

Figure 6. Replication initiation at $H M R$ was not sufficient to provide silencing function. Results from a two-dimensional origin experiment of a strain that contained ARS1 in place of natural $H M R$-E (JRY4486). Half of the DNA sample was used to examine the $A R S 1$-containing $N c o l$ fragment in its natural context $\{1\}$, and the other half was used to examine the HindIII $H M R$ fragment that contained ARS1 as its only origin (2).

within the ORC5-coding region. These new alleles of the ORC5 gene were designated orc5-1,2 and orc5-1,3.

Curiously, the new orc 5 pseudorevertants caused an even greater silencing defect than the original orc5-1 mutation, as judged by mating efficiency (Table 3 ). The origin activity of the synthetic silencer was monitored using plasmid loss-rate assays in wild-type and orc5-1 mutants and in the orc5-1,2 and orc5-1,3 pseudorevertants. In orc5-1 strains, plasmids whose only origin was the synthetic silencer were lost at a high rate. In contrast, in both pseudorevertants, the plasmid loss rate was restored to a low level (Table 3). These conclusions were confirmed by two-dimensional origin-mapping gels that revealed efficient replication initiation at the synthetic silencer in the pseudorevertants (data not shown). Thus, these new alleles of ORC5 restored viability at the restrictive temperature and allowed efficient replication initiation from the synthetic silencer, yet they provided very little silencing function.

\section{ORC functioned in silencing outside of $S$ phase}

The pseudorevertants of orc5-1 indicated that ORC had a role in replication that was mutationally separable from its function in silencing. However, these experiments did not address whether ORC had a role in silencing that could be uncoupled from its role in replication initiation. Because replication initiation is confined to $S$ phase, one way to determine whether ORC has a role in silencing independent of replication initiation is to determine whether ORC's role in silencing is restricted to $S$ phase or whether its role continues through other parts of the cell cycle. Operationally, such an experiment involves arresting the cells carrying temperature-sensitive orc mutations outside of $S$ phase at a permissive temperature and, once arrested, shifting the cells to the nonpermissive temperature. If the role of ORC in silencing were restricted to its role in replication initiation, derepression should not occur in cells shifted to restrictive conditions outside of $S$ phase. In contrast, if ORC were to function in silencing independently of replication initiation, then a shift to the restrictive temperature should cause derepression of $H M R$ at other points in the cell cycle.

To carry out these experiments, it was necessary to tune silencing to a level of sensitivity at which temperature-sensitive mutations in $O R C$ genes produced a temperature-sensitive defect in silencing. In cells containing the synthetic silencer and the HMR-I element, orc2-1 caused virtually no derepression at the permissive temperature, yet incubation at the nonpermissive temperature $\left(34^{\circ} \mathrm{C}\right)$ caused derepression of HMRa (Fig. 7A, lanes 1,$2 ; \sim 10 \%-20 \%$ of maximum measurable derepression, cf. lane 2-5|. This result was not observed for an isogenic $O R C$ strain (Fig. 7A, lanes 3,4 ) or an $O R C$ strain that contained the synthetic silencer without $H M R$-I /Fig. 7A, lanes 7-10), which was slightly compromised for silencing (Table 2). Thus, the synthetic silencer in combination with $H M R$-I effectively tuned silencing at $H M R$ such that the orc2-1 mutation produced a temperaturesensitive defect in silencing that was reflected in a1 mRNA levels.

Incubation at the nonpermissive temperature causes orc2-1 cells to lose viability. To minimize the impact of viability issues in these experiments, we used the shortest possible incubation time $(6 \mathrm{hr})$ at the restrictive temperature. In addition, two control experiments indicated that the elevated a1 mRNA in orc2-1 mutants was the result of derepression rather than a secondary feature of sick or dying cells. First, in strains containing orc2-1 and the natural $H M R$-E silencer, the temperature shift caused no appearance of a1 mRNA (Fig. 7A, lanes 11-14).

Table 3. orc5-1 pseudorevertant analysis

\begin{tabular}{llccc}
\hline Strain & $\begin{array}{l}\text { Relevant } \\
\text { genotype }\end{array}$ & $\begin{array}{l}\text { Plasmid } \\
\text { loss rate }\end{array}$ & $\begin{array}{l}\text { Mating } \\
\text { efficiency }\end{array}$ & $\begin{array}{c}\text { Doubling time } \\
\text { (min) at } 37^{\circ} \mathrm{C}\end{array}$ \\
\hline JRY4473 & wild type & 0.027 & 0.204 & 64 \\
JRY4476 & orc5-1 & 0.264 & $6.25 \times 10^{-4}$ & N.D. \\
JRY4554 & orc5-1,2 & 0.149 & $5.7 \times 10^{-5}$ & 68 \\
IRY4556 & orc-1,3 & 0.080 & $3.8 \times 10^{-5}$ & 75 \\
\hline
\end{tabular}

Plasmid loss rates, mating efficiencies, and growth rates were determined for isogenic MAT $\alpha H M R$-SS $\triangle \mathrm{I}$ strains that were ORC, orc5-1, orc5-1,2, or orc5-1,3. Plasmid loss rates and mating efficiencies were measured at $23^{\circ} \mathrm{C}$. Growth rates were measured at $37^{\circ} \mathrm{C}$. For loss rates, plasmids were used that contained the synthetic silencer as the sole origin of replication. (N.D.) Not determined. 

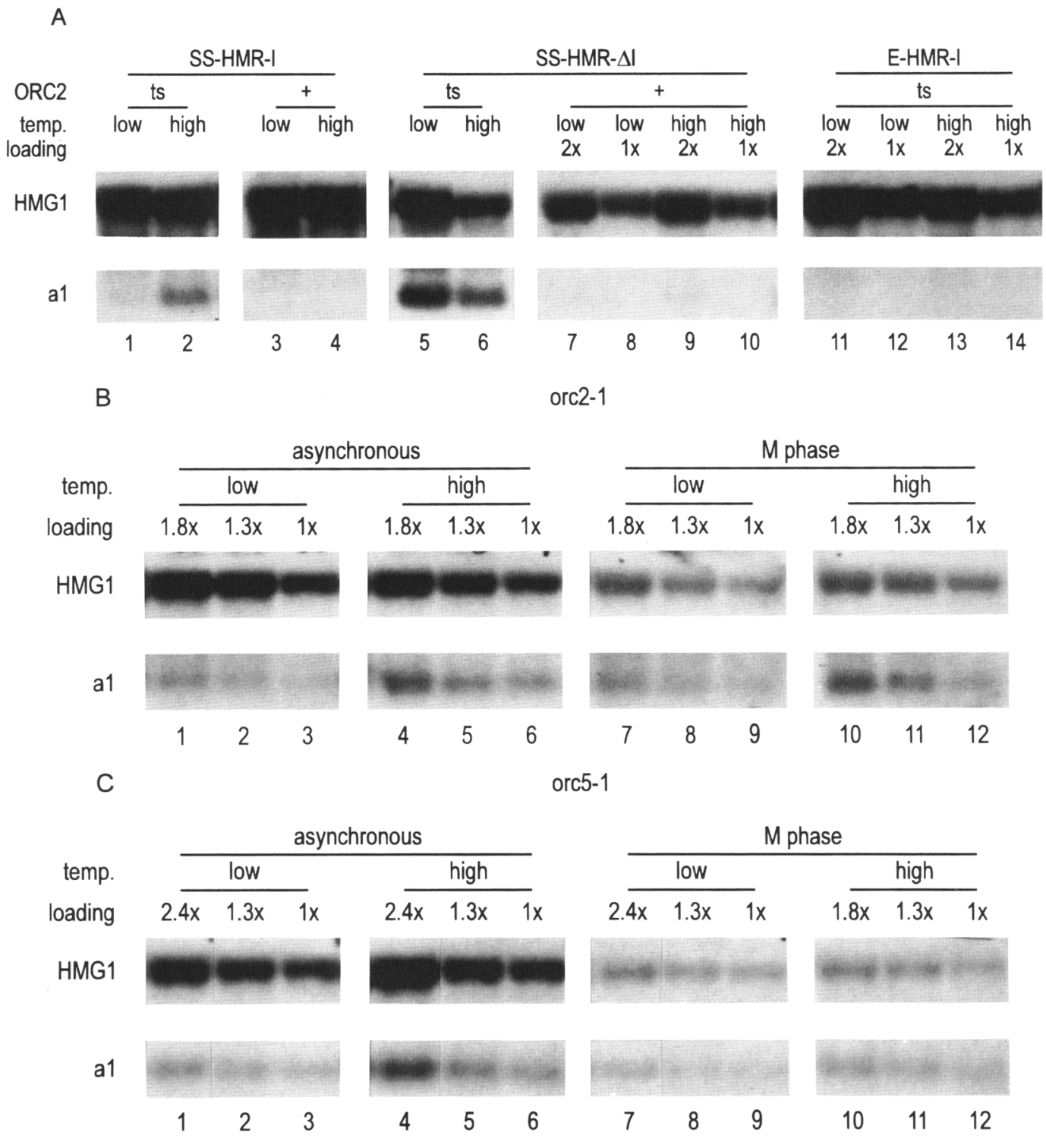

Figure 7. ORC functioned in silencing outside of $\mathrm{S}$ phase. $|A| \mathrm{RNA}$ was isolated from isogenic $O R C$ or orc2-1 strains. The relevant genotype of $H M R$ is listed at the top, and the ORC genotype is either ORC $\left(+\right.$ ) or orc $2-1$ (ts). "low" refers to $23^{\circ} \mathrm{C}$, and "high" to $34^{\circ} \mathrm{C}$. The RNA was isolated from the following strains: (Lanes 1,2) An orc2-1 strain containing the synthetic silencer and $H M R-I$ (JRY4493). The loads were normalized to equal levels of HMG1 mRNA. (Lanes 3,4) An ORC strain containing the synthetic silencer and HMR-I (JRY4492). (Lanes 5,6) An orc2-1 strain containing the synthetic silencer without HMR-I (JRY4475). In lanes 5 and 6, identical number of micrograms, as measured by spectrophotometric $A_{260} \mathrm{~nm}$, were loaded to indicate that both a 1 and $H M G 1$ mRNA decreased in orc2-1 cells incubated at the restrictive temperature. (Lanes 7-10) An ORC strain containing the synthetic silencer without HMR-I (JRY4473). (Lanes 11-14) An orc2-1 strain containing natural HMR (JRY4488). For lanes $7-14,1 \times$ refers to $\sim 20 \mu \mathrm{g}$ of RNA. (B) For these experiments, RNA was isolated from an orc2-1 strain containing the synthetic silencer and $H M R$-I (JRY4493). M phase refers to benomyl-arrested cultures. $(C)$ For these experiments, RNA was isolated from an orc5-1 strain containing the synthetic silencer and $H M R-I$ (JRY4494). M phase refers to nocodazole-arrested cultures.

Thus, appearance of a1 mRNA depended on the silencer allele present at $H M R$-E. Second, the derepression of $H M R$-E by orc2-1 was monitored as an increase in a1 mRNA level relative to HMG1 mRNA. Formally, it was possible that an apparent induction could occur if somehow HMG1 mRNA was less stable than a1 mRNA in cells shifted to the restrictive temperature. To test this possibility, the ratio of $H M G 1$ mRNA to a1 mRNA was compared at the permissive and restrictive temperatures in a strain already defective for silencing at the permissive temperature (an orc2-1 strain containing the synthetic silencer but lacking $H M R-I$; Fig. 7A, cf. lanes 5 and 6). This experiment established that at either temperature, the ratio of the steady-state level of a1 mRNA to the steady-state level of HMG1 mRNA remained unchanged. 
To evaluate the role of orc2-1 in silencing outside of S phase, exponentially growing orc2-1 cells were treated with benomyl which caused the cells to arrest in $M$ phase of the cell cycle. Half of the culture continued to incubate at $23^{\circ} \mathrm{C}$, whereas the other half was shifted to $34^{\circ} \mathrm{C}$. The culture shifted to the nonpermissive temperature accumulated more a1 transcript from $H M R$ than the culture that remained at $23^{\circ} \mathrm{C}$ (Fig. $7 \mathrm{~B}$, lanes 7,10 , cf. the ratio of a1 mRNA to HMG1 mRNA). Thus, ORC function was required in $M$ phase-arrested cells for maximal repression of $H M R$. In fact, a role for Orc2p in $M$-phase silencing was also evident at the permissive temperature; more a1 mRNA was produced in the orc2-1 cells arrested in $\mathrm{M}$ phase at $23^{\circ} \mathrm{C}$ than in an asynchronously growing culture (Fig. 7B, cf. lanes 7-9 with lanes 1-3). An isogenic ORC strain did not produce a1 mRNA when arrested in $\mathrm{M}$ phase either at $23^{\circ} \mathrm{C}$ or $34^{\circ} \mathrm{C}$ (data not shown).

To extend our analysis of ORC function in M-phase silencing, temperature-shift experiments were also performed with the orc5-1 mutation. Similar results were obtained, although as a result of the significant derepression caused by this allele even at permissive temperatures, the magnitude of derepression observed at $34^{\circ} \mathrm{C}$ was smaller (Fig. 7C). Thus, based on the examination of two different temperature-sensitive alleles of $O R C$, $O R C$ 's function in silencing was not restricted to $S$ phase.

\section{Discussion}

The discovery of ORC as the complex responsible for recognition of the ACS was a significant advance in yeast DNA replication. The next logical question was whether or not ORC, when bound to ARS elements, controls replication initiation in vivo. The discovery of orc2 and orc5 mutations on the basis of silencing defects established that ORC has a role in controlling the transcriptional competence of portions of the genome and has led to the question of whether ORC's role in silencing is coincident with or independent of its role in replication initiation.

\section{$O R C$ as a replication initiator}

Temperature-sensitive mutations in ORC2 and ORC5, which encode two different ORC subunits, both resulted in a reduction in replication initiation from ARS1. This effect was evident in cells grown at the permissive temperature. It might seem odd that temperature-sensitive mutations that grow at the permissive temperature would affect origin usage at the permissive temperature. However, the density of origins of replication in yeast chromosomes is substantially higher than would be needed to ensure replication of the genome (Dershowitz and Newlon 1993). Thus, even for origins that are affected by these orc mutations at the permissive temperature, with sufficient numbers of these origins, chromosomes would still be replicated even if individual origins initiate in only a fraction of cell divisions. Second, as shown here for the effect of orc5-1 and orc2-1 on ARS1, the synthetic silencer, and natural $H M R-\mathrm{E}$, different origins can respond differently to the same orc mutation. Therefore, it was possible that a subset of yeast origins was relatively unaffected by either orc2-1 or orc5-1 at the permissive temperature and that these origins contributed to replication of the genome in these mutants. This interpretation was supported by fork migration analysis that indicated forks coming from different origins could compensate for the lack of replication resulting from decreased initiation by some origins.

\section{$O R C$ in silencing}

Previous work established the requirement for the ACS of the synthetic silencer in both silencing and replication initiation (McNally and Rine 1991; Rivier and Rine 1992a). Because orc2-1 and orc5-1 affected both replication initiation at the synthetic silencer as well as silencing, it was possible that ORC's role in silencing was restricted to its role in replication initiation. However, two lines of evidence indicate that ORC's role in silencing was not coincident with its role in replication initiation. First, the orc2-1 and orc5-1 mutations caused quantitatively identical silencing defects yet caused different effects on replication initiation at the synthetic silencer. Second, pseudorevertants of orc5-1 were fully capable of replication initiation but were defective in silencing. This result established that the silencing function of ORC could be removed by mutation without affecting the initiation function. In effect, in these pseudorevertants the function of the synthetic silencer was reduced to that of a conventional origin. Substitution of $H M R$-E with either ARS1 or with ARSH4 provided replication initiation adjacent to $H M R$ a without providing any silencing. These experiments provided additional evidence that replication initiation in the vicinity of $H M R$ was insufficient for silencing. Thus, unlike its role in replication initiation, ORC's role in silencing may depend on its ability to interact with other factors present at the silencer that are not present at other origins of replication. Raplp is a strong candidate for this interacting protein because it binds to silencers but not to ARS1 or ARSH4. Furthermore, silencing defective alleles of RAP1 have been identified (Sussel and Shore 1991). An interaction between ORC and Raplp may create a surface that recruits Sirlp, which can bypass the requirement of the ARS consensus element and RAP1-binding site at HMR-E (Chien et al. 1993). Alternatively, the silencer origin may need to fire late during $S$ phase to establish or maintain a silent state. Thus, the pseudorevertants of orc5-1 need not necessarily disrupt a specific interaction with Raplp or Sir proteins but may instead lead to early replication of $H M R$.

Although these studies established that replication initiation from a silencer was not sufficient to cause silencing of adjacent sequences, the data did not address whether replication initiation from a silencer was necessary for silencing. At present, there is no clear resolution of this issue. For example, the ORC complex binds 
the $H M L$-E silencer in vitro, yet this silencer exhibits no detectable replication initiation (Dubey et al. 1991; Bell et al. 1993). Nevertheless, ORC is required for full silencing of $H M L$ (S. Loo, C. Fox, J. Rine, R. Kobayashi, B. Stillman, and S. Bell, in prep.). This result suggests that ORC's role in silencing is independent of its role in replication initiation. However, this interpretation must be tempered by several unresolved possibilities. First, the silencing mechanisms operating at both $H M R$ and $H M L$ may depend on replication initiation at the silencer, but to different extents. For example, previous work has shown that silencing consists of two functionally distinguishable processes: the establishment of silencing and its maintenance. In principle, better establishment could compensate for weaker maintenance and vice versa, resulting in a silenced locus. If replication at a silencer were required to establish silencing, perhaps $H M R$ depends on more frequent establishment events, corresponding to the obvious origin activity at the $H M R-\mathrm{E}$ silencer. In contrast, $H M L$ may be silenced by a combination of infrequent establishment events and better maintenance of the repressed state, explaining the absence of detectable origin activity at the $H M L$ silencers. Second, there may be a fundamental difference between the mechanism of silencing at $H M R$ and $H M L$ such that replication initiation would be required at $H M R$ but not at $H M L$. Finally, replication initiation may not be essential for silencing yet may still contribute to the kinetics or pattern by which $H M R$ and $H M L$ become silenced in exponentially growing cultures. Alleles of $O R C$ genes that are defective in replication from the $H M R$-E silencer yet still function in silencing $H M R$ would help to resolve this issue.

The lack of an effect of orc2-1 and orc5-1 on replication initiation from the natural $H M R$-E silencer is consistent with the complex nature of this element. Analysis of the natural $H M R$-E silencer has revealed the existence of two ARS elements within the natural HMR-E silencer and many near matches to the ACS (Brand et al. 1987). It appears likely that at the permissive temperature, the presence of additional ORC-binding sites spares this element from suffering the reduction in function experienced by simpler elements lacking this sequence redundancy.

From the perspective of silencing, a particularly intriguing aspect of this work was the discovery that ORC function was required during $M$ phase of the cell cycle for the silencing of $H M R$. Biochemical studies have indicated that ORC remains bound to the ACS of origins throughout the cell cycle (Diffley and Cocker 1992; Diffley et al. 1994), but there has been no information on whether ORC provides a function at any time other than $S$ phase.

Previous work has suggested that the ACS of the $H M R$-E silencer, and by inference ORC as well, plays a role in the establishment of repression at $H M R$ during $\mathrm{S}$ phase (Miller and Nasmyth 1984; Rivier and Rine 1992b; Sussel et al. 1993). The results presented here suggest that the ORC complex plays a role in the maintenance of the repressed state in the $M$ phase of the cell cycle. Even at permissive temperatures, the orc2-1 mutation caused a decrease in silencing in cells arrested in $M$ phase that was not evident in cycling cells. This effect was increased by shifting the $M$ phase-arrested cultures to the nonpermissive temperature for the orc mutation. The increased sensitivity of silencing to orc mutations in $\mathrm{M}$ phase could be explained if ORC were required for maintenance of silencing throughout the cell cycle and were also required for the establishment of silencing during $S$ phase. Defects in maintenance caused by these orc mutations could be reversed if the cells were allowed to pass through $\mathrm{S}$ phase to reestablish the silent state, explaining why cycling cells did not exhibit as great a loss of silencing. New alleles of ORC2 and ORC5, which are conditionally defective for silencing but not growth, will help explore these issues. Alternatively, the silent chromatin structure at $H M R$ could be particularly sensitive to silencing defects in general during $M$ phase, as recently observed for telomeres (Aparicio and Gottschling 1994).

The central issue raised by the experiments reported here and elsewhere is whether ORC's role as a replication initiator is mechanistically related in any way to its role in silencing. It is possible that ORC's role in replication initiation is independent of its role in silencing. However, there is increasing evidence that the processes of replication and transcriptional repression are coupled. For example, mutations in the gene encoding Drosophila proliferating cell nuclear antigen, a processivity factor for DNA replication, suppress position-effect variegation (Henderson et al. 1994). Thus, whatever the mechanism by which ORC functions in silencing, roles for replication proteins in transcriptional repression may be conserved among eukaryotes.

\section{Materials and methods}

\section{General}

Yeast rich medium (YPD), minimal medium (YM), amino acid and base supplements, and standard yeast genetic methods were as described (Rose et al. 1989). Recombinant DNA methods were as described (Sambrook et al. 1989). To generate $H M R$ ARS1(JRY4486), the HMR portion of pIR1950 was integrated into JRY3009. Strains used for this report are presented in Table 4 .

\section{Two-dimensional origin and fork migration analysis}

The isolation and analysis of replication intermediates were performed essentially as described except that cultures were grown at $23^{\circ} \mathrm{C}$ (Rivier and Rine 1992a). The probes used to detect specific fragments are described in the figures. For fork migration analysis, the enzymes used for in-gel digestion were from New England Biolabs, and the procedure followed was essentially as described (Brewer et al. 1992).

Fork migration analysis was quantified with a PhosphorImager (Molecular Dynamics, Sunnyvale, CA). For quantitation of fork migration patterns at $A R S 1$ and to the left of the synthetic silencer, the signal intensity for the two different fork arcs was compared between segments that were generated from the same portion of the original undigested forks. For quantitation of fork migration patterns on the right side of the synthetic silencer, a slightly different method was used because of the consistently 
Fox et al.

Table 4. Strains used in this study

\begin{tabular}{|c|c|}
\hline Strain & Genotype (source) \\
\hline W303-1A & MATa ade2-1 his3-11,15 leu2-3,112 trp1-1 ura3-1 can1-100 (R. Rothstein, pers. comm.) \\
\hline W303-1B & MAT $\alpha$ ade2-1 his3-11,15 leu2-3,112 trp1-1 ura3-1 can1-100 (R. Rothstein, pers. comm.) \\
\hline JRY3009 & W303-1A; MAT $\alpha$ \\
\hline JRY4012 & W303-1A; $A D E 2$ lys $2 \Delta$ \\
\hline JRY2726 & MATahis4 (D. Botstein, pers. comm.) \\
\hline JRY4125 & W303-1B; orc2-1 \\
\hline JRY4249 & JRY3009; orc5-1 \\
\hline JRY4473 & JRY3009; HMR-SS $\Delta \mathrm{I}$ \\
\hline JRY4474 & JRY3009; HMR-SSars ${ }^{-} \Delta \mathrm{I}$ \\
\hline JRY4475 & JRY3009; HMR-SS $\Delta \mathrm{I}$ orc2-1 \\
\hline IRY4476 & JRY3009; HMR-SS $\Delta \mathrm{I}$ orc5-1 \\
\hline JRY4477 & JRY3009; HMR-SS $\Delta \mathrm{I} \operatorname{sir} 2 \Delta:: L E U 2$ \\
\hline JRY4478 & JRY3009; HMR-SS $\Delta \mathrm{I} \operatorname{sir} 2 \Delta:: L E U 2$ orc $2-1$ \\
\hline JRY4479 & JRY3009; HMR-SS $\Delta \mathrm{I}$ sir2 $\Delta:: L E U 2$ orc5-1 \\
\hline JRY4480 & JRY3009; HMR $\Delta \mathrm{I}$ \\
\hline JRY4481 & JRY3009; HMR $\Delta \mathrm{I}$ orc $2-1$ \\
\hline JRY4482 & JRY3009; HMR $\Delta \mathrm{I}$ orc $5-1$ \\
\hline JRY4483 & JRY3009; HMR $\Delta I$ sir2 $\Delta:: L E U 2$ \\
\hline JRY4484 & JRY3009; HMR $\Delta I$ sir $2 \Delta:: L E U 2$ orc $2-1$ \\
\hline JRY4485 & JRY3009; HMR $\Delta \mathrm{I}$ sir $2 \Delta::$ LEU2 orc $5-1$ \\
\hline JRY4486 & JRY3009; HMR-ARS1 $\Delta \mathrm{I}$ \\
\hline JRY4487 & JRY3009; HMR-ARSH4 $\Delta \mathrm{I}$ \\
\hline JRY4488 & JRY3009; orc2-1 \\
\hline JRY4492 & JRY3009; $H M R$-SS \\
\hline JRY4493 & JRY3009; HMR-SS orc2-1 \\
\hline JRY4494 & JRY3009; HMR-SS orc5-1 \\
\hline JRY4554 & JRY3009; HMR-SS $\Delta \mathrm{I}$ orc5-1,2 \\
\hline JRY4556 & JRY3009; HMR-SS $\Delta \mathrm{I}$ orc5-1,3 \\
\hline
\end{tabular}

Unless otherwise noted, the strains listed in this table were from the laboratory collection or were constructed for experiments in this paper.

faint signal caused by the small part of the $H M R$ probe that could distinguish $H M R$ from $M A T$. Fork migration analysis liberates linear molecules from fork shaped molecules during the in-gel digestion prior to migration in the second dimension. Digestion of fragments containing forks coming from the left produced linear molecules that migrated below the end of the original fork (Fig. 3A, second panel). In contrast, digestion of fragments containing forks coming from the right produced linear molecules that were displaced horizontally from the unreplicated fragments (Fig. 3A, third panel). Therefore, the relative intensity of these two linear species reflected the relative direction of replication forks in this region. Because, on average, each forked molecule coming from the left produces two linear fragments that hybridized to probe, whereas each forked molecule coming from the right produced only one linear fragment, the intensity of the signal from the linear molecules below the end of the original fork was divided by two for quantitation. Application of this approach to fork migration analysis to the right of the acs $^{-}$synthetic silencer, for example, revealed that $50 \%$ of the forks that replicated this region were from each direction, in complete agreement with the data obtained from analysis of the left side of this mutant silencer (Fig. 3B).

\section{Plasmid loss-rate measurements}

Plasmids used to determine loss rates were based on pIR954 (McNally and Rine 1991), a derivative of YIp5 containing a 1.6$\mathrm{kb} C E N 6$ fragment and a $1.3-\mathrm{kb}$ EcoRI-FspI $H M R \mathrm{p} 8 \Delta \mathrm{E}$ fragment. Three derivatives of pJR954 were constructed that con- tained the synthetic silencer (pJR950), ARS1 (pJR1469), and ARSH4 (pJR 1470) as the only origin of replication. Each of these origins was inserted at the XhoI site that marked p $8 \Delta \mathrm{E}$. ARS1 was cloned as an $\sim 220$-bp EcoRI-Xbal fragment from pARS1/ WTA provided by Y. Marahrens and B. Stillman (1992); ARSH4 was cloned as an $\sim 380$-bp EcoRI-PstI fragment from pAB9 provided by M. Mitchell Smith (University of Virginia, Charlottesville). All of these sites were made flush with Klenow polymerase for insertion at the XhoI site of $\mathrm{p} 8 \Delta \mathrm{E}$ in $\mathrm{pJR} 954$.

To determine loss rates, transformants were grown into stationary phase in minimal medium lacking uracil. The stationary-phase culture was used to inoculate rich medium, and cells were plated from the liquid rich media to selective media after the initial inoculation and after 12 doublings. The resulting colonies were counted, and plasmid loss rates were calculated as described (McNally and Rine 1991).

Isolation of silencing-defective but

replication-competent alleles of ORC5

Ten independent cultures of an orc5-1 strain (JRY4476) were grown at $23^{\circ} \mathrm{C}$ to an $A_{600}=1.0$ and plated onto individual plates of YPD at $37^{\circ} \mathrm{C}$ at a density of $1 \times 10^{8}$ cells per plate. Three to five temperature-resistant revertants were recovered from each plate. Two independent revertants were analyzed in the experiments reported here.

orc5-1,2 and orc5-1,3 were cloned as described (Orr-Weaver and Szostak 1983) using a plasmid that contained a genomic complementing clone of ORC5. The plasmid was cut to gener- 
ate a gapped plasmid that was then transformed into the pseudorevertant orc5 strains described in Table 3. Plamids from transformants were recovered and retransformed into orc5-1 strains and tested for viability at $37^{\circ} \mathrm{C}$ and silencing defects at $30^{\circ} \mathrm{C}$. Plasmids able to complement the growth defect of orc5-1 but not its silencing defect were sequenced and confirmed as second site mutations. The sequence of the ORC5 gene will be presented elsewhere (S. Loo, C. Fox, J. Rone, R. Kobayashi, B. Stillman, and S. Bell, in prep.|.

\section{Analysis of al mRNA}

RNA was isolated from $\sim 20$ OD units of log-phase cells as described (Van Ardell et al. 1987). Glyoxal denaturation of the RNA was followed by electrophoresis through a sodium phosphate-agarose gel (pH 7.0). Biodyne A transfer membranes (VWR) were used for blotting. Hybridizations were performed in Northern hybridization buffer ("5 Prime to 3 Prime", Inc.) using the supplied protocol. DNA probes were prepared using the Amersham Multiprime labeling kit. Blots were exposed to Kodak XAR film at $-80^{\circ} \mathrm{C}$ in the presence of an intensifying screen for 2-3 days. In Figure 7B, the HMG1 loading control was exposed to film for 1 day, whereas the a1 mRNA was exposed to film for 2-3 days. This procedure was necessary because the level of a1 mRNA in this orc2-1 strain was a small fraction of the HMG1 mRNA (see Fig. 7A, lanes 1,2).

\section{Temperature-shift experiments}

Log-phase cells $\left(A_{600}=\sim 1.0\right)$ growing in YPD were harvested by centrifugation and resuspended in YPD at an $A_{600}=2.0$. This concentrated culture $(2.5 \mathrm{ml})$ was added to $22.5 \mathrm{ml}$ of medium preincubated at either $34^{\circ} \mathrm{C}$ or $23^{\circ} \mathrm{C}$. For $M$ phase arrest experiments, $2.5 \mathrm{ml}$ of the concentrated culture was added to $22.5 \mathrm{ml}$ of medium at $23^{\circ} \mathrm{C}$ containing benomyl at $40 \mu \mathrm{g} / \mathrm{ml}$. For some experiments, nocodazole was used instead at $10 \mu \mathrm{g} / \mathrm{ml}$ with similar results. The cells with no inhibitor were allowed to continue incubating for $6 \mathrm{hr}$. The optimum induction of a1 mRNA in the orc2-1 strain (JRY4493) occurred after $6 \mathrm{hr}$ at $34^{\circ} \mathrm{C}$, and this time period was used for all experiments. At $34^{\circ} \mathrm{C}$, the majority of orc $2-1$ cells arrested within the first cell cycle, and after $6 \mathrm{hr}$ at $34^{\circ} \mathrm{C}$, few $(\sim 3 \%)$ live orc2-1 cells could be recovered at $23^{\circ} \mathrm{C}$. Most of the orc5-1 cells (JRY4494) incubated at $34^{\circ} \mathrm{C}$ for $6 \mathrm{hr}$ could be recovered at $23^{\circ} \mathrm{C}(\sim 90 \%)$. For $\mathrm{M}$ phase-arrest experiments, the concentrated culture was exposed to the inhibitor at $23^{\circ} \mathrm{C}$ for $\sim 3 \mathrm{hr}$. Arrest was monitored microscopically. When cells were $>95 \%$ arrested, they were harvested by centrifugation and resuspended in $2.5 \mathrm{ml}$ of YPD containing inhibitor. The $2.5 \mathrm{ml}$ were then transferred to media preincubated at $23^{\circ} \mathrm{C}$ or $34^{\circ} \mathrm{C}$ that also contained inhibitor. After $6 \mathrm{hr}$, the cells were harvested by centrifugation and quick frozen in a dry ice-ethanol bath. Before harvest, the cells were reexamined microscopically. In these experiments, the cell cycle block had been maintained and individual arrested cells appeared normal and nondeformed. In separate experiments, the viability of isogenic, ORC, orc2-1, and orc5-1 cells was determined by washing out benomyl and plating cells at $23^{\circ} \mathrm{C}$. Recovery of live cells after $\mathrm{M}$-phase arrest was somewhat variable. However, it was possible to obtain approximately as many live orc2-1 cells as wild-type cells after incubation in benomyl at $34^{\circ} \mathrm{C}$ for $6 \mathrm{hr}(\sim 90 \%$ recovery), suggesting that the restrictive temperature was not as detrimental to orc2-1 cells arrested in $\mathrm{M}$ phase as orc2-1 cells growing asynchronously.

The amounts of RNA loaded in the $1 \times$ lanes for the experiments in Figure 7, B and C, varied. HMG1 mRNA and a1 mRNA were recovered equally well from cells grown at either temperature (Fig. 7A, lanes 5,6), but the recovery of these mRNAs decreased relative to $A_{260}$ units at $34^{\circ} \mathrm{C}$. For the low-temperature orc samples, $1 \times$ was $\sim 10-15 \mu \mathrm{g}$ of total RNA as measured by $A_{260}$ units, and $1 \times$ for the high-temperature samples was $\sim 20-30 \mu \mathrm{g}$.

\section{Acknowledgments}

We thank York Marahrens for sending us pARS1/WTA and M. Mitchell Smith for sending us pAB9. C.A.F. and S.L. thank David Rivier for two-dimensional protocols and lively discussions. C.A.F. thanks Bonita Brewer for technical advice on fork migration analysis and for $A R S 1$ probes and Georgana Barnes and members of her lab for advice on the $M$ phase-arrest experiments. We also thank members of the lab for helpful discussions and P. Errada for making a sir2 $2:: L E U 2$ strain that was used to generate several of the strains in Table 4. C.A.F. thanks M.D.Sheets for support and encouragement. This work was supported by a Leukemia Society of America postdoctoral fellowship (C.A.F.), a Howard Hughes Medical Institute predoctoral fellowship (S.L.), a grant from the National Institutes of Health (GM31105 to J.R.), and a Mutagenesis Center grant from the National Institute of Environmental Health Sciences for support of core facilities (P3OESO1896-12).

The publication costs of this article were defrayed in part by payment of page charges. This article must therefore be hereby marked "advertisement" in accordance with 18 USC section 1734 solely to indicate this fact.

\section{References}

Abraham, J., J. Feldman, K.A. Nasmyth, J.N. Strathern, A.J.S. Klar, J.R. Broach, and J.B. Hicks. 1982. Sites required for position-effect regulation of mating-type information in yeast. Cold Spring Harbor Symp. Quant. Biol. 47: 989-998.

Abraham, J., K.A. Nasmyth, J.N. Strathern, A.J.S. Klar, and J.B. Hicks. 1984. Regulation of mating-type information in yeast: Negative control requiring sequences both $5^{\prime}$ and $3^{\prime}$ to the regulated region. J. Mol. Biol. 176: 307-331.

Aparicio, O.M. and D.E. Gottschling. 1994. Overcoming telomeric silencing: A trans-activator competes to establish gene expression in a cell-cycle-dependent way. Genes \& Dev. 8: 1133-1146.

Bell, S.P. and B. Stillman. 1992. ATP-dependent recognition of eukaryotic origins of DNA replication by a multiprotein complex. Nature 357: 128-134.

Bell, S.P., R. Kobayashi, and B. Stillman. 1993. Yeast origin recognition complex functions in transcription silencing and DNA replication. Science 262: 1844-1849.

Brand, A.H., L. Breeden, J. Abraham, R. Sternglanz, and K. Nasmyth. 1985. Characterization of a "silencer" in yeast: A DNA sequence with properties opposite to those of a transcriptional enhancer. Cell 41: 41-48.

Brand, A.H., G. Micklem, and K. Nasmyth. 1987. A yeast silencer contains sequences that can promote autonomous plasmid replication and transcriptional activation. Cell 51: 709-719.

Brewer, B.J. and W.L. Fangman. 1987. The localization of replication origins on ARS plasmids in S. cerevisiae. Cell 51: 463-471.

- 1991. Activation of replication origins within yeast chromosomes. Annu. Rev. Cell Biol. 7: 375-402.

1993. Initiation at closely spaced replication origins in a yeast chromosome. Science 262: 1728-1731. 
Brewer, B.J., D. Lockshor, and W.L. Fangman. 1992. The arrest of replication forks in the rDNA of yeast occurs independently of transcription. Cell 71: 267-276.

Campbell, J.L. and C.S. Newlon. 1991. Chromosomal DNA replication. In The molecular and cellular biology of the yeast Saccharomyces cerevisiae: Genome dynamics, protein synthesis, and energetics (ed. J.R. Broach, E.W. Jones, and J.R. Pringlel, pp. 41-146. Cold Spring Harbor Laboratory Press, Cold Spring Harbor, New York.

Chien, C.T., S. Buck, R. Sternglanz, and D. Shore. 1993. Targeting of SIR 1 protein establishes transcriptional silencing at HM loci and telomeres in yeast. Cell 75: 531-541.

Dershowitz, A. and C.S. Newlon. 1993. The effect on chromosome stability of deleting replication origins. Mol. Cell. Biol. 13: $391-398$.

Diffley, J.F.X. and J.H. Cocker. 1992. Protein-DNA interactions at a yeast replication origin. Nature 357: 169-172.

Diffley, J.F.X., J.H. Cocker, S.J. Dowell, and A. Rowley. 1994. Two steps in the assembly of complexes at yeast replication origins. Cell 78: 303-316.

Dubey, D.D., L.R. Davis, S.A. Greenfeder, L.Y. Ong, J. Zhu, J.R. Broach, C.S. Newlon, and J.A. Huberman. 1991. Evidence suggesting that the ARS elements associated with silencers of the yeast mating-type locus $H M L$ do not function as chromosomal DNA replication origins. Mol. Cell. Biol. 11: 53465355.

Feldman, J.B., J.B. Hicks, and J.R. Broach. 1984. Identification of sites required for repression of a silent mating-type locus in yeast. J. Mol. Biol. 178: 815-834.

Foss, M., F.J. McNally, P. Laurenson, and J. Rine. 1993. Origin recognition complex (ORC) in transcriptional silencing and DNA replication in S. cerevisiae. Science 262: 1838-1844.

Henderson, D.S., S.B. Satnam, T.A. Grigliatti, and J.B. Boyd. 1994. Mutagen sensitivity and suppression of position-effect variegation result from mutations in mus209, the Drosophila gene encoding PCNA. EMBO /. 13: 1450-1459.

Kayne, P.S., U. Kim, M. Han, J.R. Mullen, F. Yoshizaki, and M. Grunstein. 1988. Extremely conserved histone H4 N-terminus is dispensable for growth but essential for repressing the silent mating loci in yeast. Cell 55: 27-39.

Kimmerly, W.K. 1988. "Cis and trans-acting regulators of the silent mating type loci of Saccharomyces cerevisiae." Ph.D. thesis, University of California, Berkeley, CA.

Laurenson, P. and J. Rine. 1992. Silencers, silencing, and heritable transcription states. Microbiol. Rev. 56: 543-560.

Li, J. and I. Herskowitz. 1993. Isolation of ORC6, a component of the yeast origin recognition complex, by a one hybrid system. Science 262: 1870-1874.

Mahoney, D., R. Marquardt, G. Shei, A. Rose, and J. Broach. 1991. Mutations in the $H M L$-E silencer of Saccharomyces cerevisiae yield metastable inheritance of transcriptional repression. Genes \& Dev. 5: 605-615.

Marahrens, Y. and B. Stillman. 1992. A yeast chromosomal origin of DNA replication defined by multiple functional elements. Science 255: 817-823.

McNally, F.J. and J. Rine. 1991. A synthetic silencer mediates SIR-dependent functions in Saccharomyces cerevisiae. Mol. Cell. Biol. 11: 5648-5659.

Micklem, G., A. Rowley, J. Harwood, K. Nasmyth, and J.F. Diffley. 1993. Yeast origin recognition complex is involved in DNA replication and transcriptional silencing. Nature 366: 87-89.

Miller, A.M. and K.A. Nasmyth. 1984. Role of DNA replication in the repression of silent mating-type loci in yeast. Nature 312: $247-251$.

Orr-Weaver, T.L. and J.W. Szostak. 1983. Yeast recombination:
The association between double-strand gap repair and crossing-over. Proc. Natl. Acad. Sci. 80: 4417-4421.

Pillus, L. and J. Rine. 1989. Epigenetic inheritance of transcriptional states in S. cerevisiae. Cell 59: 637-647.

Rine, J. and I. Herskowitz. 1987. Four genes responsible for a position-effect on expression from $H M L$ and $H M R$ in Saccharomyces cerevisiae. Genetics 116: 9-22.

Rivier, D.H. and J. Rine. 1992a. An origin of DNA replication and a transcription silencer require a common element. Science 256: 659-663.

- 1992b. Silencing: The establishment and inheritance of stable, repressed transcription states. Curr. Opin. Genet. Dev. 2: 286-292.

Rose, M.D., F. Winston, and P. Heiter. 1989. Laboratory course manual for methods in yeast genetics. Cold Spring Harbor Laboratory Press, Cold Spring Harbor, New York.

Sambrook, J., E.F. Fritsch, and T. Maniatis. 1989. Molecular cloning: A laboratory manual. Cold Spring Harbor Laboratory Press, Cold Spring Harbor, New York.

Sussel, L. and D. Shore. 1991. Separation of transcriptional activation and silencing function of the RAPl-encoded repressor/activator protein 1 : Isolation of viable mutants affecting both silencing and telomere length. Proc. Natl. Acad. Sci. 76: 2340-2344.

Sussel, L., D. Vannier, and D. Shore. 1993. Epigenetic switching of transcriptional states: cis- and trans-acting factors affecting establishment of silencing at the HMR locus in Saccharomyces cerevisiae. Mol. Cell. Biol. 13: 3919-3928.

Van Ardell, S.W., G.L. Stetler, and J. Thorner. 1987. The yeast repeated element sigma contains a hormone-inducible promoter. Mol. Cell. Biol. 7: 749-759. 


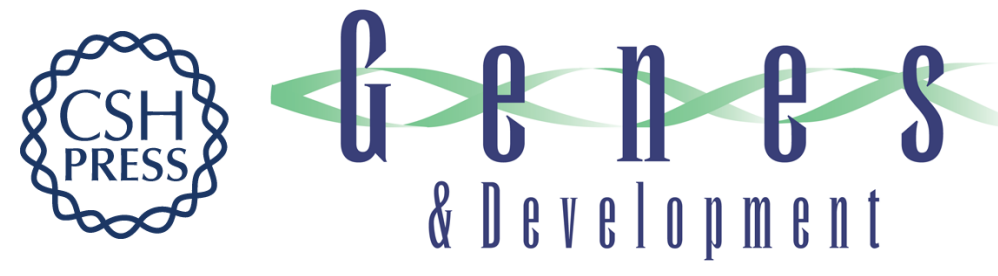

\section{The origin recognition complex has essential functions in transcriptional silencing and chromosomal replication.}

C A Fox, S Loo, A Dillin, et al.

Genes Dev. 1995, 9:

Access the most recent version at doi:10.1101/gad.9.8.911

References This article cites 35 articles, 15 of which can be accessed free at:

http://genesdev.cshlp.org/content/9/8/911.full.html\#ref-list-1

License

Email Alerting

Service

Receive free email alerts when new articles cite this article - sign up in the box at the top right corner of the article or click here.

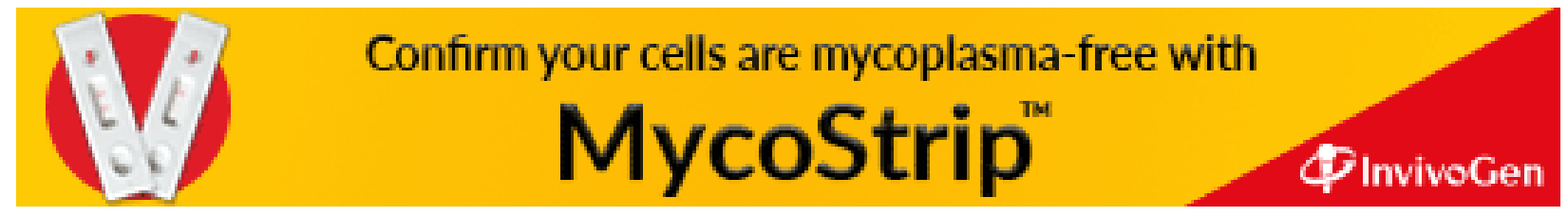

